\title{
INFLUENCE OF ANESTHESIA TYPE ON INTRAOCULAR PRESSURE DURING SPINE SURGERY IN PRONE POSITION
}

DOI: 10.36740/WLek202001120

\author{
Mykola V. Lyzohub ${ }^{1}$, Marine A. Georgiyants², Kseniia I. Lyzohub', Juliia V. Volkova ${ }^{3}$, Dmytro V. Dmytriiev4, \\ Kostiantyn D. Dmytriiev ${ }^{4}$ \\ "SI"SYTENKO INSTITUTE OF SPINE AND JOINT PATHOLOGY OF NATIONAL ACADEMY OF MEDICAL SCIENCE", KHARKIV, UKRAINE \\ 2KHARKIV MEDICAL ACADEMY OF POSTGRADUATE EDUCATION, KHARKIV, UKRAINE \\ ${ }^{3}$ KHARKIV NATIONAL MEDICAL UNIVERSITY, KHARKIV, UKRAINE \\ ${ }^{4}$ VINNYTSIA NATIONAL PIROGOV MEMORIAL MEDICAL UNIVERSITY, VINNYTSIA, UKRAINE
}

\begin{abstract}
The aim was to examine intraocular pressure (IOP) during lumbar spine surgery in PP under general vs spinal anesthesia and to compare it with volunteers in PP. Materials and methods: We performed randomized prospective single institutional trial. Patients were operated in PP with fixation of 1-2 spinal segments. Patients of group I $(n=30)$ were operated under SA, group $2 \mathrm{~A}(\mathrm{n}=25)$ - under TIVA (total intravenous anesthesia) with $45^{\circ}$ head rotation (left eye was located lower, than right eye), group $2 B(n=25)$ - under TIVA with no head rotation (both eyes were located on the same level). IOP was measured with Maklakov method before and after surgery. Volunteers ( $\mathrm{n}=$ 20) were examined before and 90 minutes after lying in $P P$ with $45^{\circ}$ head rotation.

Results: In all patients and volunteers after lying in PP, we found that IOP have increased. In SA patients and in TIVA patients with no head rotation there was no difference between eyes. The most significant raise of IOP was found in the dependent eye of IIA group patients: it was higher than in volunteers and I group patients ( $p<0.01$ ), and IIB group patients $(\mathrm{p}<0.05)$. In SA patients there was no difference in IOP comparing to volunteers.

Conclusions: IOP increased in PP in healthy people and patients under anesthesia (SA and TIVA). IOP in SA patients did not differ from volunteers. IOP increased superiorly in the dependent eye in TIVA patients.
\end{abstract}

KEY WORDS: intraocular pressure, spinal surgery, prone position, spinal anesthesia, intravenous anesthesia

Wiad Lek. 2020;73(1):104-106

\section{INTRODUCTION}

Postoperative visual loss (POVL) is a quite rare, but devastating complication of surgeries performed in prone position which pathophysiology is not clearly understood [1]. It occurs in approximately $0.2 \%$ of surgeries in prone position [2]. The main mechanism of POVL is thought to be ischemic optic neuropathy in $89 \%$ of cases. Rarely, it can be a result of central retinal artery occlusion, cortical blindness, and posterior reversible encephalopathy [3]. Risk factors of POVL could be major surgeries in prone position, significant blood loss, intraoperative hypotension, diabetes mellitus, obesity, direct pressure on the eyeball, history of oncologic disease, and vasopressor requirement. Restoration potential of optic nerve is very poor, thus POVL in majority of cases is irreversible [4]. The mechanism of POVL is thought to be increasing of intraocular pressure and decreasing of perfusion pressure [5]. That is why the most effective prophylaxis of it is considered to be $10^{\circ}$ head elevation, prevention of abdominal compression and direct eye pressure, hypovolemia, and hypotension.

Lumbar spine surgery can be performed under general and spinal anesthesia [6,7]. Spinal anesthesia has several advantages over general anesthesia, including lower blood loss, lower postoperative pain intensity, and lower incidence of postoperative nausea and vomiting. All currently available researches of intraocular pressure (IOP) during surgeries in prone position were performed in patients under general anesthesia [8]. Moreover, all cases of POVL were associated with general anesthesia [9].

\section{THE AIM}

Aim of the study was to examine changes of IOP during lumbar spine surgery in prone position under general vs spinal anesthesia and to compare them with healthy volunteers lying in prone position.

\section{MATERIALS AND METHODS}

After approval of local ethics committee we performed randomized prospective single institutional trial. Investigation was performed in SI "Sitenko Institute of Spine and Joint Pathology NAMS of Ukraine". We examined 20 healthy volunteers and 80 ASA I-II patients with degenerative lumbar spine diseases. Patients were operated in 
Table 1. Intraocular pressure $(\mathrm{mm} \mathrm{Hg})$ in patients and healthy volunteers $(\mathrm{M} \pm \mathrm{SD})$.

\begin{tabular}{ccccc}
\hline & Before surgery & Before surgery & After surgery & After surgery \\
\hline & Right eye & Left eye & Right eye & Left eye \\
\hline Group I & $15.9 \pm 1.0$ & $15.7 \pm 1.1$ & $17.2 \pm 1.2^{*}$ & $17.8 \pm 1.5^{*}$ \\
\hline Group IIA & $16.1 \pm 1.4$ & $16.2 \pm 1.4$ & $18.4 \pm 1.4^{*}$ & $21.2 \pm 1.9^{* * *}$ \\
\hline Group IIB & $15.9 \pm 1.4$ & $16.0 \pm 1.3$ & $18.8 \pm 1.7^{*}$ & $18.6 \pm 1.5^{*}$ \\
\hline Healthy volunteers & $16.3 \pm 1.3$ & $16.4 \pm 1.2$ & $16.9 \pm 1.0$ & $18,2 \pm 1.2^{* * *}$ \\
\hline
\end{tabular}

* $p<0.05$ comparing to the first examination

${ }^{* *} p<0.05$ comparing to the non-dependent eye

prone position with transpedicular screw fixation of 1-2 segments (PLIF - Posterior Lumbar Interbody Fusion). The length of surgery did not exceed 3 hours. Patients of group I ( $\mathrm{n}=30,11$ men, 19 women, age $46 \pm 12$ years) were operated under spinal anesthesia at level L2-L3 or L3-L4 with bupivacaine heavy $0.5 \%-3.5 \mathrm{ml}$. After local anesthetic injection patients lied in supine position during $10 \mathrm{~min}$ and then were turned into prone position. During the operation they could change the position of their head. Patients of group $2 \mathrm{~A}$ ( $\mathrm{n}=25,10$ men, 15 women, age $45 \pm 13$ years) were operated under TIVA (total intravenous anesthesia - propofol, fentanyl, rocuronium in standard dose). The head was rotated $45^{\circ}$ (left eye was located lower, than right eye). Patients of group 2B ( $n=25,11$ men, 14 women, age $43 \pm 14$ years) were operated under TIVA, but the position of the head was $90^{\circ}$ (both eyes were located on the same level). Prone position was standard horizontal with pillows under pelvis that allowed abdomen to sag freely. IOP was examined with Maklakov method by single experienced examiner before surgery and immediately after it. Healthy volunteers ( $\mathrm{n}=20,9$ men , 11 women, age $49 \pm 12$ years) were examined in supine position, and 90 minutes after lying in prone position. Their head was rotated $45^{\circ}$. Exclusion criteria were surgeries longer than 3 hours, blood loss more than 1 liter, history of ophthalmologic pathology. We used simple randomization. All patients signed an informed consent for participation.

Statistical analysis was performed with IBM SPSS 9.0. Normal distribution was confirmed with Colmogorov-Smirnov test. To evaluate the difference between groups Student $\mathrm{t}$-test was used with Bonferoni correction.

\section{RESULTS AND DISCUSSION}

Before surgery there was no difference in IOP between groups of patients and healthy volunteers (Table 1).

It found that IOP have increased in patients of all groups and healthy volunteers after lying in prone position. In patients under spinal anesthesia (Group I) and in patients under TIVA with head $90^{\circ}$ there was no difference between eyes. The most significant increasing of IOP was found in the dependent eye of IIA group patients: it was higher than in healthy volunteers and I group patients ( $\mathrm{p}$ $<0.01)$, and IIB group patients ( $\mathrm{p}<0.05)$. Interestingly, that in patients of group I (spinal anesthesia) there was no significant difference comparing to healthy volunteers. Maximal measured level of IOP was $26 \mathrm{~mm} \mathrm{Hg}$. None of the patients had postoperative ophthalmologic complications.

Blood supply of the optic nerve depends on the perfusion pressure. Ocular perfusion pressure is the difference between mean arterial pressure on the level of eye and IOP or venous pressure (depending which one is bigger). Local arteriolar vasoconstriction can lead to ischemia regardless normal mean arterial pressure [10]. Like brain tissue, optic nerve blood supply has autoregulation, that can fail in up to $20 \%$ of healthy people [11].

Changes of IOP in different body positions in non-anesthetized people were investigated by Malihi M. [12]. It was shown, that IOP in dependent eye had been higher. In the paper Lee T, et al. [13] proved that in prone position in non-anesthetized people IOP increases more significantly in the eye, that is positioned lower. Lam A. showed, that in prone position in healthy volunteers IOP increases very quickly (during 8 minutes) [14]. Interestingly, they found much more significant changes in IOP in prone position, than we did. In supine position in patients under general anesthesia IOP usually decreases [15]. That is why POVL does not occur after surgery in supine position. Deniz M. et al. demonstrated increasing of IOP under general anesthesia in prone position. Their result was similar to our data according to a more significant changes in the dependent eye [16]. Authors recommend to use their results in patients with oneeye glaucoma: head position of 45 degrees with healthy eye lower than glaucoma eye in prone position may be beneficial for them.

According to our data we could recommend to use spinal anesthesia in patients with increased IOP as it has minimal influence on it.

\section{CONCLUSIONS}

1. Intraocular pressure increases in prone position in healthy people and patients under anesthesia (spinal and TIVA).

2. Changes of IOP in prone position in patients under spinal anesthesia did not differ from healthy volunteers.

3. The most significant changes of IOP were found in the dependent eye of patients under intravenous anesthesia. 


\section{REFERENCES}

1. Mendel E, Stoicea N, Rao R, et al. Revisiting Postoperative Vision Loss following Non-0cular Surgery: A Short Review of Etiology and Legal Considerations. Front Surg. 2017:4(34). doi: 10.3389/fsurg.2017.00034

2. Epstein N. How to avoid perioperative visual loss following prone spinal surgery. Surg Neurol Int. 2016:7(13):328-330. doi: 10.4103/21527806.182543

3. Nickels T, Manlapaz M, Farag E. Perioperative visual loss after spine surgery. World J Orthop. 2014;5(2):100-106.

4. Kamel I, Barnette R. Positioning patients for spine surgery: Avoiding uncommon position-related complications. World J Orthop. 2014;5(4):425-443. doi: 10.5312/wjo.v5.i4.425 PMCID: PMC4133449

5. Mason DePasse J, Palumbo M, Haque M, et al. Complications associated with prone positioning in elective spinal surgery. World J Orthop. 2015;6(3):351-359. doi: 10.5312/wjo.v6.i3.351

6. Attari M, Mirhosseini S, Honarmand A, Safavic M. Spinal anesthesia versus general anesthesia for elective lumbar spine surgery: A randomized clinical trial. J Res Med Sci. 2011;16(4):524-529.

7. Lyzogub M. Spinal anesthesia for lumbar spine surgery in prone position: plain vs heavy bupivacaine. European Journal of Anaesthesiology. 2014;31:133.

8. Lee L. Perioperative visual loss and anesthetic management. Curr Opin Anaesthesiol. 2013;26(3):375-381. doi:10.1097/ AC0.0b013e328360dcd9.

9 GroverV, Jangra K. Perioperative vision loss: A complication to watch out. J Anaesthesiol Clin Pharmacol. 2012;28(1):11-16. doi: 10.4103/09709185.92427

10. Hayreh S. Anterior ischemic optic neuropathy. Clin Neurosci. 1997;4(5):251-263.

11. Pillunat L, Anderson D, Knighton R, et al. Autoregulation of human optic nerve head circulation in response to increased intraocular pressure. Exp Eye Res. 1997;64(5):737-744.

12. Malihi M, Sit A. Effect of head and body position on intraocular pressure. Ophthalmology. 2012;119(5): 987-991. doi: 10.1016/j. ophtha.2011.11.024.

13. Lee $T, Y_{00}$ C, Kim Y. Effects of different sleeping postures on intraocular pressure and ocular perfusion pressure in healthy young subjects. Ophthalmology. 2013;120(8):1565-170. doi: 10.1016/j. ophtha.2013.01.011.
14. Lam A, Douthwaite W. Does the change of anterior chamber depth or/ and episcleral venous pressure cause intraocular pressure change in postural variation? Optom Vis Sci. 1997;74(8):664-667.

15. Murphy D. Anesthesia and intraocular pressure. Anesth Analg. 1985;64(5):520-530.

16. Deniz $M$, Erakgün $A$, Sertöz $N$, et al. The effect of head rotation on intraocular pressure in prone position: a randomized trial. Braz J Anesthesiol. 2013;63(2):209-212. doi: 10.1016/j.bjane.2012.03.008.

\section{ORCID and contributionship:}

Mykola V. Lyzohub - 0000-0003-4776-1635 A,B,C,D,E,F

Marine A. Georgiyants - 0000-0002-1373-7840 B,C,D,E,F

Kseniia I. Lyzohub - 0000-0001-9149-7208 B,C,D,E,F

Juliia V. Volkova - 0000-0001-8187-7450 B,C,D,E,F

Dmytro V. Dmytriiev - 0000-0001-6067-681X C,D,E,F

Kostiantyn D. Dmytriiev - 0000-0003-2269-6291 C,D,E,F

\section{Conflict of interest:}

The Authors declare no conflict of interest

\section{CORRESPONDING AUTHOR Kostiantyn D. Dmytriiev}

Vinnytsia National Pirogov Memorial Medical University

56, Pirogova str., 21018, Vinnytsia, Ukraine

e-mail: kostya011993@gmail.com

Received: 11.04 .2019

Accepted: 14.11 .2019

A - Work concept and design, B - Data collection and analysis, C - Responsibility for statistical analysis, D-Writing the article, $\mathbf{E}$-Critical review, $\mathbf{F}$ - Final approval of the article 